\title{
Preface to the Proceedings of the International Conference "Translation Industry: Theory in Action"
}

\section{Dear Reader,}

We are pleased to introduce the Proceedings of the "Translation Industry: Theory in Action" (TITA 2020) International Research-to-Practice Conference for Translators, Young Scholars and Students, which took place online on 11-12 December 2020 at the Institute of Philology, Taras Shevchenko National University of Kyiv, Ukraine.

The perception of translation as industry suggested by the name of the conference indicates the direction of its further development in Ukraine following the four prior stages mainly related to the major events in the country's history:

- critical period preceding World War I;

- emergence of translation as a scientific and academic discipline between the two world wars;

- post-war development within the former Soviet Union;

- establishment of translation studies as an interdisciplinary field since the end of the $20^{\text {th }}$ century [1].

It is no surprise that the current state of translation studies in Ukraine correlates with their interdisciplinary progress worldwide [2: 4], i.e. for 30 years since the country gained independence the local translators and interpreters have been following the global trend tinging it with national traditions.

The International Conference "Translation Industry: Theory in Action" has become a platform for the wide discussion of numerous theoretical aspects and practical challenges the translation science and translation industry are facing today. The problems raised, and the solutions offered, contributed a lot to a better understanding of an array of understudied areas, including the following:

- $\quad$ cognitive processes underlying the information processing and decision-making in translation;

- $\quad$ strategic planning of the translator's activity in the broader context of intercultural communication;

- delivery of culture-specific concepts and 'national spirit' via translation;

- the role of literary translation in the nation-building and language-development processes;

- continuity and parcellation of the literary translation process as a part of the national culture development;

- translator qualification, employment and professional growth in the light of new approaches to measuring translation quality;

- new technologies in translation: adoption by translation community and influence on translation quality.

Aimed at enhancing the links between translation studies and translation industry, the conference has instituted a forum for the intense dialogue of scholars, educators, students, practical translators, and translation business operators. This gave a unique opportunity to 
create awareness of the industry needs and expectations from university graduates and scholars, and on the other hand, to inform the field practitioners of the most recent developments and the newest ideas explored by the theorists of translation. The conference created the platform for building partnerships between educational institutions and businesses for internships, summer schools, employment prospects, exchanging best practices etc.

This event has become a pioneer in fostering knowledge sharing in the online format. It brought together the scholars and professionals from different countries (Croatia, Czech Republic, Germany, Poland, Spain, USA), through time and space, to exchange the novel visions of translation industry, trends in international communications, problems and solutions in implementing new technologies. These discussions helped bridge the gaps in understanding the main concepts, theories, terminology, as well as expectations from translators and translation in today's global business community. The conference has set the example for the institutions of higher education and scholarship to follow in the pursuit of career readiness and gainful employment of their graduates, on the global scale.

Conference presentations and discussions showed the growing scope of translation science and practice, the field diversification and interconnectedness with other industries or areas of study. The contributions by field practitioners created an understanding of the need for specialised translators focusing on a certain industry or field of practice, such as domestic/international/European law, economics and business, culture and literature, etc. Besides, the qualification in translation, such professionals require the knowledge of their specific subject, as well as conceptual systems, workplace culture and practices of the countries they are translating for.

With its scope of topics, diversity of approaches, and vast industry engagement, this conference is definite to leave an unprecedented legacy for the further development of the translation studies in Ukraine.

This volume of the Proceedings of the International Conference "Translation Industry: Theory in Action" mainly focuses on the transformation of the interdisciplinary tendencies of the development of translation studies into an industry handling large quantities of long texts quickly and efficiently, backing up theoretical research with professional experience, where practical accomplishments underpinned by translation theory define the future of this field.

The "industrial" tendencies of Ukrainian translation with a national colouring are reflected in the volume's five sections with each of them spanning from the translation of individual linguistic units to texts of varying size: Literary Translation; Interpreting. Translation and Modern Technologies; Specialised Translation; Audiovisual Translation; Translation and Business. Translation for the EU.

The Literary Translation section offers papers of three types varying in the scope of the source material they draw on. One article is historical, discussing the heritage of the Ukrainian translator Bohdan Kravtsiv. Three other contributions focus on rendering separate linguistic units into Ukrainian: they encompass American culture-specific items designating status; metaphors of war; lexical and phraseological units in American university discourse. Four more papers of this section turn to the translation of lengthy texts which include the poetical prose of the classical and contemporary English short stories; reception of literary works in the original and translation; J. M. Coetzee's Disgrace and its Russian and Ukrainian interpretations; beliefs about Ruthenians in the German-language literature of Austrian Galicia and its Ukrainian translations.

The two articles of the section entitled Interpreting. Translation and Modern Technologies explore globalising and localising strategies of translating English news headlines into Ukrainian from the media rhetorical perspective, on the one hand, and the potential for computer-assisted interpreting in student training in Ukraine, on the other. 
Like the Literary Translation section the seven papers of the Specialised Translation part split into three groups differing in the scope of translation material studied. Two contributions address the translation of pharmacological and institutional academic terminology. The other two apply the constructionist approach to explaining the translation of the units referring to blind people and structures employed in President Trump's inaugural address concluding that people communicate and translate using constructions entrenched in their memories rather than separate words. Two more papers focus on the translation of discourse units: paratextual elements accompanying news items and invectives in present-day political communication.

The Audiovisual Translation section discusses the interpretation of slang, amateur subtitling and songs from films while the Translation and Business section extended by a paper on translation for the European Union dwells on strategic competence as the core of the translator's qualification; on collaboration between translation business and academia in Ukraine; on translation within "Association4U" EU-funded technical aid project (Phase I) aimed at supporting the approximation of Ukrainian laws to the European Union legislation.

We hope the conference participants are on the right track developing translation as industry, which means quick and efficient handling of large quantities of lengthy texts.

We are deeply thankful to every contributor of this volume.

We also express our gratitude to all reviewers for their insightful comments which helped the authors to improve the papers.

We extend our thanks to the members of the conference organizing team for their hard work.

We hope that the readers will appreciate the volume.

\section{References}

1. T. Shmiher. History of Ukrainian Translation Studies (Smoloskyp, Kyiv, 2009).

2. L. Venuti. The Translation Studies Reader, 1-8 (Routledge, London, 2000).

\section{Editors of the conference proceedings:}

Prof. Dr. habil. Tetiana Andrienko, Westcliff University, California, USA (atetiana@westcliff.edu);

Prof. Dr. habil. Serhiy Potapenko, Kyiv National Linguistic University, Kyiv, Ukraine (potapenkoknlu@gmail.com);

Prof. Dr. habil. Liudmyla Slavova (Taras Shevchenko National University of Kyiv, Kyiv, Ukraine slavovall16@gmail.com ). 